\title{
Tšuktšid III
}

$\underline{\text { Ülo Siimets }}$

\section{Karudest}

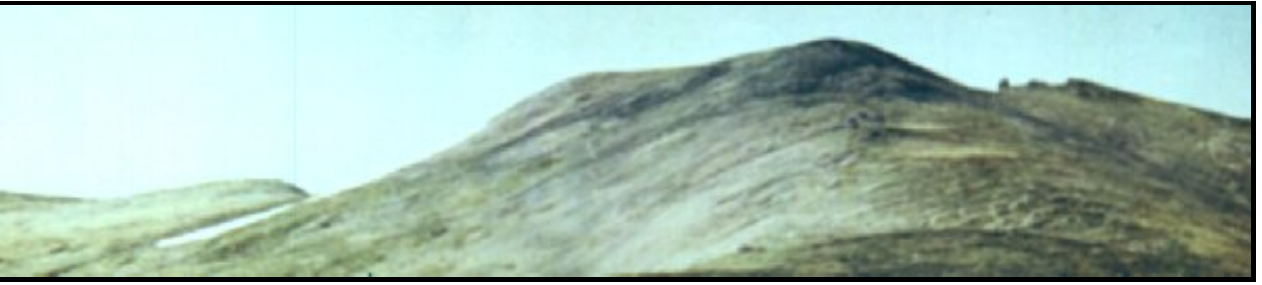

11. jaanuaril läksime kolhoosi kontorisse tööd küsima.

Olime astunud kolhoosi kontorisse, et arutada oma tulevast ametit, kui tundrast saabus haukudes koerarakend, millel istus põdranahkses riietuses vanamees. Ta sidus koerad posti külge ning tuli kontori poole.

«Näe, Uttel tuli nahku üle andma,» märkis esimees.

Uksele koputati ja vana astus sisse.

«Eteki (tšuktši keeles tere), kuidas jaht läks?» küsis esimees sisseastunud tšuktšilt.

«Eteki, eteki. Väga kehva. Kolmkümmend kaks jänest, viis rebast ja üks «rassamahha» (vene keeles ahmi ehk kaljukassi nimi). Loomi on väheks jäänud.»

«Aasta alguseks on hea küll, aga kas karusid ka on?»

«Leidsin ühe hurtsiku,» muheles Uttel.

«Näed, meile on kauged külalised tulnud. Peab külalislahkust üles näitama. Näita koobast. Ma annan sulle uue vintpüssi.»

Oli näha, et see jutt vanamehele ei meeldi. Ta tõmbas kulmu kortsu ja ütles: «Liha meil on. Kuu aega tagasi toodi ju üks külla. Ma tulin tegelikult loa järele.»

Esimees vaikis mornilt, kirjutas siis mõned read paberile ja vanamees lahkus kiiresti.

Juba eelmisel päeval oli selgunud, et tšuktši rahvuskülades kehtib kuiv seadus. Alkoholi müüakse riiklikel pühadel ja ka siis on normiks üks või kaks pudelit inimese kohta vastavalt püha tähtsusele. Tundrast tulijal oli õigus viiele pudelile alkoholile.

«Sellised nad on,» sõnas kolhoosi esimees meile, kui uks vanamehe järel oli sulgunud, «harva tahavad nad teisi oma saladustesse pühendada.» Vaikis siis hetke ja jätkas: «Mis ma teiega peale hakkan? Kas teil dokumente üldse on? Mida te üldse teha oskate?»

«Me tahaksime põdrakarja minna,» lausus Eerik.

«Paljugi, mis teie tahate. Väljas on kuuskümmend kraadi külma. Katsuge kõigepealt külas hakkama saada.»

Ulatasime oma dokumendid, mida ta hakkas sirvima. Dokumente oli meil kaasas üksjagu. Paistis, et ta mõtles veel ikka karujahile, sest mida rohkem mõtles, seda pahuramaks ta näoilme muutus. Korraga talle sattus kätte minu müürsepa-tunnistus, mis tõstis kohe esimehe tuju.

Ta naeratas ja ütles: «Te mul päris paberitega ehitajad kohe. Egas midagi, lähetegi ehitusele tööle.»

«Aga mina ju ei ole,» sõnas Eerik vahele.

«Pole viga, küll õpid. Laost saate endale korralikud riided. Ega linnamehe riietes Kaug-Põhjas ringi ei käida.» 
Nii me lahkusime kontorist, saadetuna laomehest, kes meie ees ühe kuuriukse avas. Ladu oli otsast ääreni kaupa täis. Seal oli mitmesuguseid kaste küll pudelite, küll konservidega. Riiulitel vedeles nahku ja riideid. Meile anti proovida, millised riided meile parajad on. Riietatuna vatipükstesse, karusnahkse kraega mitmekordsete hõlmadega vatijopesse, põdranahksetesse torbastesse, põdranahksetesse kinnastesse, tundus polaarkliima isegi talutavana.

Meid pandi kaasüürilisteks endise piirivalvuri Vasja Startsevi juurde, kes viibis parasjagu traktoribrigaadiga $200 \mathrm{~km}$ kaugusel ehituspuidu järel. Too koht pidi asuma kusagil Anadõri jõe ääres ja sinna oli suur laev suvel väga kõrge puidumäe «suurelt emamaalt» toonud.

Läksime Niina juurde, et oma asju ära tuua. Kaugelt silmasime õues lahti rakendatud koeri, kes tundusid tuttavatena. Ukse avas Niina.

«Eteki,» tervitasime me teda.

«Eteki, eteki. Näe, isa saabus tundrast tagasi.»

Laua ääres istus meile kontorist tuttav Uttel.

«Kakomei (tšuktši imestushüüe), või teie olete minu tütre sõbrad sealt kaugelt maalt, kus ta õppimas käis. Väga tore. Ja sina oledki see Jelo. Tütar on sinust mulle rääkinud, aga ausalt ma ei uskunud, et te nii kaugele maale talle külla tulete. Eteki, eteki.»

Otsisin seljakotist välja pudeli «Vana Tallinnat». Vana silmad lõid särama. Lauale ilmusid punane kalamari ja suitsetatud keta balõkk.

Valasin klaasid täis.

«Küll on hea jook. Proovige sõbrad, kuidas meie kala maitseb,» lausus ta pärast esimest lonksu.

«Teie istuge ja ajage juttu. Ma käin natukene ära,» sosistas Niina mulle kõrva.

Lasime ketal ja kalamarjal hea maitsta. Liköörile oli hea kanget kuuma teed peale juua. Vana ei söönud midagi ja ainult tõstis klaasi. Pöörasime ääri-veeri jutu karudele ja nende kommetele.

Selgus, et karud ei lange talveunne nagu suslikud või koopaoravad, vaid nad on valmis iga hetk ärkama neid segavate häälte peale. Koopasse ei lähe nad ka ükskõik mis ajal, sest nad tunnevad väga hästi ära ilmastiku muutused ja lähevad koopasse üks päev enne püsiva lume ja püsivate külmade saabumist. Koopas magavad nad tavaliselt viis kuud. Emakarud võivad koopas olla isegi pool aastat. Selle aja jooksul loomad ei söö, ei joo, ei erita ainevahetuse jääke.

Küsimusele, kas karud ikka ründavad inimest, vastas vana jahimees, et loomulikult, aga siis, kui nad on haavatud või peavad kaitsma oma poegi. Tavaliselt ei tohi karule selga pöörata, muidu neil võib tulla isu sind rünnata. Kallale tungivad nad niisuguse kiirusega, et harva jõuab ohver mingi ime läbi põgeneda. Kätte saades karud skalpeerivad inimese. Kui inimene kaotab teadvuse, siis karud jätavad ta maha või matavad okste alla, et hiljem maiustada tema roiskunud lihaga. Ka karudele meeldib «will-will».

«Jaht karule tema koopas on olnud iidsetest aegadest peale ainult julgete meeste ala. Olid ajad, kus karudele peeti jahti ainult jahinugade ja odadega,» rääkis Uttel, «nüüd pole mehed enam endised. Mis viga on mitmest vintpüssist nottida maha vana karu, kuid katsuge teda noa ja odaga surmata.»

Vahepeal kolksatas uks ja Niina saabus tagasi kotitäie pudelitega. Kuuldes isa viimaseid sõnu, lisas ta, et noorest peast oli tema isa mitugi korda, nuga käes, karuga võidelnud, aga nüüd on ta kahjuks vanaks jäänud.

Küsisin Uttelilt, kuidas on võimalik nii suurt ja tugevat looma, kui seda on karu, lihtsalt noa abil surmata. Ta vastas, et selline jaht ei toimugi ainult noa abil, ning jutustas: 


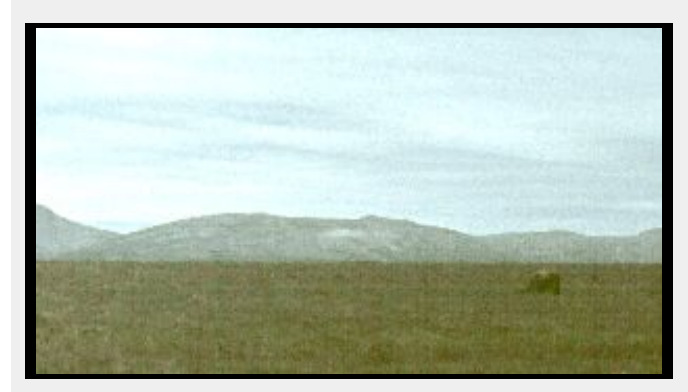

«Kõigepealt pead leidma muidugi karu. Siis jälitad teda. See võib kesta hulk aega, vahel isegi päevi, sest loomi on väheseks jäänud. Sa hiilid tal taga, nii et ta sind ei märka, ja siis kui karu on lagedale, põõsastevabale kohale jõudnud, siis röögatad. Liiga kõvasti ei tohi karjatada, sest muidu loom ehmub liigselt ja jookseb ära. Kui karu pöörab ümber, siis katsud teda vihale ajada. Enesekaitseks ja rünnakuks tõuseb karu alati kahele jalale püsti. Siis jooksed kiiresti tema juurde ja torkad talle oda rindu ning vajutad teise otsa maa sisse. Peale seda tapad karu noa abil. Selleks otstarbeks on meil spetsiaalne, lühikene, umbes pooleteise meetri pikkune, tugeva varrega oda. Pikema varre purustab karu kergesti ja siis sul enam pääsu ei ole. Odaots rinnus, tormab ta edasi ja surmab vaenlase. Ei ole targemat looma kui on karu.»

Hiljem pidime seda tõdemust korduvalt kuulma. Selles olid veendunud kõik kohalikud elanikud, nagu selleski, et teades karusõnu võid sa ennast peaaegu alati karu vastu kaitsta, sest karurahvas saab väga hästi aru tšuktši keelest.

Tšuktšid usuvad, et mitte ainult karudel, vaid kõikidel metsloomadel on oma rahvas ja oma majapidamine. Pruunkarudel on elamu osaliselt maa sisse kaevatud ja kaetud oksarisuga. Valgetel karudel on oma külad avamerel jäätükkide vahel. Majad on neil ehitatud jääst, neid valgustavad rasvalambid.

Loomad võivad kergesti muuta oma kuju ja suurust, nagu seda teevad vaimud. Vajaduse korral võivad nad võtta inimese kuju ja elada koos inimestega. Sel juhul säilitavad nad oma paremad loomalikud omadused. Näiteks jääkaru-inimesest saab hea hülgekütt. Rebane-inimesel säilib hea lõhnataju jne.

Ka ketlja pidi aeg-ajalt ennast ilmutama looma kujul ning inimesed ei tunne teda ära. Ainult kaasasündinud šamaaniomadustega inimesed pidid paha vaimu ära tundma, aga seda ka mitte alati.

Utteli tuju tõusis iga klaasiga ja lõpuks oli ta tänu Niina keelitamisele nõus meid jahile kaasa võtma. Arvatavasti aitas meelemuutusele tublisti kaasa arusaamine, et ülemustega pole kasulik pahuksis olla. On ju kolhoosi esimees rahvuskülas «kapten laevas». Rahvuskülas - nagu eespool märgitud - kehtis kuiv seadus. Alkoholi müüdi ainult kolhoosi esimehe eriloal. Viinaluba kirjutati välja perekondlike sündmuste ja kaugete külaliste saabumise puhul. Samuti oli õigus alkoholiloale inimestel, kes naasid puumajadega külla pärast pikka aega tundras viibimist. Sellest tulenes mitmeid huvitavaid seiku. Näiteks otsustasid poiss ja tüdruk viinaloa saamiseks kiiresti abielluda. Mõni aeg hiljem lahutati jne.

Ilma kolhoosi esimehe nõusolekuta pole võimalik rahvuskülla sõita ega sealt lahkuda, lennukipileteid saab osta ainult kolhoosi esimehe kirjaliku loaga. Kui sul õnnestubki kuidagi külast lahkuda, siis järgmises asustatud punktis, mis asub tavaliselt 300-400 km kaugusel, pead sa paratamatult pöörduma miilitsajaoskonda, et saada täiendavat luba lennuks Venemaa siserajoonidesse. Seal võtab miilitsaülem raadio teel ühenduse kolhoosi esimehega ja küsib, kas anda luba edasisõiduks või ei. Anadõris on selline templiga kirjalik luba piirivalvurite jaoks kõige tähtsamaks dokumendiks. 
Ülemus oli lubanud Uttelile uue vintpüssi anda. Uut vintpüssi saada oli samuti väga raske.

Otsustasime jahile minna neljakesi: esimees, Uttel, Eerik ja mina.

Öö saabudes keeras vana Uttel ennast oma lemmikkoera Paleki kõrvale põrandale magama ja meie kiirustasime oma asjadega uude korterisse.

Järgmisel hommikul, 12. jaanuaril, tõttasime esimehe juurde ja teatasime talle uudist. See tegi talle rõõmu. Et ilm oli väga külm, $-56^{\circ}$, siis soovitas ta oodata ilma soojenemist, mida raadio oli lähemal ajal lubanud.

Kuna meil oli üks püss kahe peale, siis viskasime kulli ja kirja, kes tulistab ja kes fotografeerib. Liisk andis võidu Eerikule ja seega jäi püss tema kätte.

Meil olid ainult ühed suusad. Need olid kitsad Pärnu lauad. Meie uues korteris seisid korterinaabri omad. Eerik tegi need oma torbaste jaoks parajaks. Proovisime küla ümbruses sõita, aga ilm oli siiski liiga külm ja me läksime korterisse tagasi. Kirjutasime koju ja sõpradele kirju. Neid sai terve hunnik ja viisime postkontorisse.

Kahe päeva pärast, 14. jaanuaril, oligi väljas ainult -27 kraadi külma ja me otsustasime järgmisel hommikul kell seitse liikuma hakata. Ka üks traktor pidi sõitma selles suunas metsa palkide järele, nii et osa teed pidi olema võimalik saaniga sõita. Seega oli siin kusagil isegi metsa.

Uttel lubas meiega raielangil kohtuda. Ta pidi sinna sõitma oma koerarakendiga. Sealt pidi veel kaksteist kilomeetrit tema jahionnini olema.

15. jaanuari hommikul kolistaski traktorist meie ukse taga ja tormas edasi ühte töökaaslast peale võtma. Väljas oli külmemaks läinud. Kraadiklaas näitas -36 kraadi. Lootsime, et päeva peale läheb soojemaks, kuigi mis päevast sa räägid, kui mõni tund ainult valge on. Ladusime kompsud, pambud, püssi saani äärele ja läks minekuks. Sõit oli meeldejääv. Istusime saanil, taguots tahtis kangeks külmuda. Meenus jutustus doktor Resleinist, kellele 1817. aastal anti korraldus minna SrednajaKolõmale, et panna piir suurele süüfilise puhangule, ja kes vaatamata oma kehvale varustusele, otsustas asuda koheselt teele. Ta sõitis Jakutskist oktoobrikuus välja. Külma tõttu tuli vahepeal hobuselt maha ja jooksis hobuse kõrval, et sooja saada. Nii läbis ta küll $3000 \mathrm{~km}$, kuid külmetas endal jalad. Tee lõpuosa läbis ta kanderaamil, mässituna nahkadesse. Srednaja-Kolõmale jõudes lõikas ta ise oma mõlemalt jalalt varbad. Kahjuks suri ta kuus kuud hiljem ja maeti kohalikule surnuaiale.

Ka meid ähvardas sama - külmumise oht. Saan värises ja rappus. Iga väiksemagi künka või kühmu kohal lendasime üles ja siis jälle alla. Kohati ronis traktor üle kivide, siis saan nagu korraks seisatas, et seda kiiremini traktorile järele lohiseda. Kohati oli tee kaldus ja me lendasime ühelt küljelt teisele. See põrgulik raputamine ja väristamine tüütas väga ära ja peale selle hakkas külm üha rohkem jõudu näitama. Kadestasime hirmsasti mehi, kes olid kabiinis endale koha leidnud. Sooja saamiseks pidime aeg-ajalt traktorile järele jooksma.

Kui traktor koos saaniga ühest kallakust alla vuhises, vihisesid suusad laia kaarega tee kõrvale lumme. Masin müdises sopka külge mööda üles. Suuski korjates jäime temast maha, sibasime suusad õlal traktorile järele. Kahjuks oli masin kaugele sõitnud ja kabiinis olijad ei märganud midagi. Katsu aga joosta vatiriietes! Arvan, et kes seda kordki proovinud on, ei pea seda just meelakkumiseks. Pealegi raskendasid jooksu suusad.

Kui me lõpuks sopka otsa jõudsime, nägime traktorit järgmise sopka taha kadumas. Ikkagi ei oldud meie kadumist märgatud. Otsustasime natukene aega raisata ja panime suusad alla. Kahjuks olid suusakepid saani peale jäänud. 
Eerik sai esimesena suusad alla ja juba ta rühkis kallakut pidi selles suunas, kuhu oli kadunud traktor.

Poole mäe peal ta nagu takerdus korraks, jäi jalgadele ja liugles oru põhja. Kui mina hooga samasse kohta jõudsin, siis kostis terav praksatus ja juba ma veeresin uperkuuti mäest alla. Niisiis oli minu suusanina kivi leidnud. Traktor oli suure lume kivilt pühkinud, Eerik oma suuskadega oli viimase lumejäägi riibunud ja ma olin märganud seda liiga hilja, et kõrvale põigata. Tõusin ja koperdasin teistele järele.

Eerik rühkis juba järgmise sopka otsa. Sealt vaatas ta tagasi ja hõikas, et traktor on seisma jäänud. See andis jõudu ja ma rühkisin teiste poole.

Kui olime asjad jälle saanile ladunud ning ennast sinna toetanud, siis saime mahti üksteisele otsa vaadata. Keset Eeriku punetavat nägu valendas valge nina. Ka tema püüdis mulle midagi seletada. Lõpuks taipasime mõlemad ja püüdsime nina lumega hõõruda. Oli selline tunne, nagu oleks ninale lõke tehtud. 40-kraadise külma käes lumi üksiti sulas ja külmus. Taipasime seda liiga hilja ja käisime hiljem paar kuud punetavate ninadega ringi. Õigem oleks muidugi ütelda, et nina läks paiste ja punni ning tilkus nagu sulav külmunud kartul. Selle reisi lõpuni oli nina enamiku ajast kindas. Jooksime ja lõdisesime vaheldumisi, kuni hommikul kella kümneks raielangile jõudsime.

Siinne mets kujutas endast kõige tüüpilisemat metsatundrat. Ainult Koola poolsaarel kasvavate üksikute kuuskede asemel olid siin lehised. Meil kui tulevastel metsameestel tekkis juba algul raskusi sellise puistu täiuse määramisega, sest siin ajas üks puu teist taga. See tähendab, et vabalt võis kahe puu vahele kasvama panna kümme puud. Kus elab sellises metsas karu, jäi meile arusaamatuks. Mõnikümmend meetrit eemal nägime mööda lund silkavat oravat. Kuna traktor peatus metsameeste soojaku juures ning meil oli aega, siis kiirustasime loomale järele. Meie kahtlused leidsid kinnitust. Siinsed oravad erinesid tõepoolest Eesti oravatest. Nad olid hallid, musta seljaga ning saba oli täiesti must. Meie lähenemisel ronis orav puu otsa. Paistis, et ta eriti ei kartnud, sest ta jäi kolme meetri kõrgusel asuvalt oksalt meile kelmikalt otsa vaatama. Küllap oli tal inimestega nii vähe kokkupuuteid, et ta ei osanud ohtu aimatagi.

Samas löödi soojakuuks pauguga kinni ja me vaatasime üle õla tagasi. Kui me pilgud uuesti puu poole pöörasime, oli orav kadunud. Nägime teda paar meetrit ülevalpool lehisetüvel ja taipasime, miks orav on mustjashall - ta oli lehisetüvega täiesti kokku sulanud. Kui me poleks teadnud, et puutüvel on orav, siis me poleks osanud teda märgata.

Läksime tagasi metsameeste putka juurde - see oli tavaline laudadest kokkulöödud ehitis, mille sees olid narid ja raudvaadist tehtud ahi. Transpordi kergendamiseks oli ta ehitatud traktorisaanile. Kui tee juba kruusides auras ja esimehe poolt pakutud lonks piiritust keelepaelad lahti päästis, saime kohalike metsameestega tuttavaks.

Traktorist Stepan Drjagik oli Tšukotkale sõitnud Kirovi oblasti lõunaosast, kus ta oli töötanud traktoristina. Siia oli ta tulnud raha pärast ja sellepärast, et pärast kolmeaastast elamist Kaug-Põhjas lubatakse inimesel valida elukoht ükskõik millises linnas Nõukogude Liidus, kindlustatakse elamispinnaga ja antakse autoostu luba.

Tema kaaslane Miša Bogratšov oli pärit Bilibino lähistelt. Ta oli brigaadis kõige noorem, ainult kaheksateist-aastane. Rahvuselt oli ta belamuut. Kodust oli ta lahkunud, sest isa oli pärast naise surma uuesti abiellunud. Uue naisega oli tal juba kaks last, ning Miša ei tahtnud neid segada. Pealegi ta ei saanud kasuemaga eriti hästi läbi. Ta oli aasta töötanud Bilibino aatomielektrijaama ehitusel, aga hing oli tundrasse tagasi kutsunud. Nüüd oli ta tagasi metsas. Brigaadi kuulusid veel Ženja Berjozkin ja Vasja Startsev, aga nemad olid läinud traktoriga Anadõri äärde saematerjali järele. 
Stepan jutustas, et mõned aastad tagasi oli ta Zelinski lähedal metsas raietöödel. Hommikul tööle sõites nägid nad karu, kes neid nähes tõusis tagakäppadele. Vaeseke oli takerdunud vanasse metsaveotrossi. Kuna sealkandis olid karud looduskaitse all - see tähendab, et neid võis lasta ainult loa alusel, siis otsustati vana lampjalg traktori abil vabastada. Ent kuidagi ei suudetud puu külge kinnitatud terastrossi puruks rebida. Nii jäi karu vangistusse järgmise hommikuni, kui tuldi tagasi suurte tangidega. Igor juhtis ettevaatlikult oma traktori TDT-40 karu juurde, laskis kilbi alla ja surus looma ettevaatlikult kilbiga vastu puud. Teine metsamees lõikas tangidega terastrossi läbi. Traktor sõitis ära, kuid karu ilmselt ei taibanud veel, et ta on vaba.

Stepan otsustas mesikäppa hirmutada. Ta lülitas sisse tagurpidikäigu ja andis signaali. See oli karule liig mis liig. Ta hüppas vihaselt urisedes traktori kilbile ja püüdis käppa läbi metallvõre traktori aknast sisse ajada. Õnneks see korda ei läinud. Traktoristil ei jäänud muud üle, kui kilp maha lasta ja ka karu nõnda maha raputada. Metsaisand ilmselt ei mõistnud neid kavatsusi ja ronis raevukalt mörisedes tagasi. Siis vajutas Stepan uuesti signaalnupule, tee peal seisev autojuht tegi sedasama. Karu kuulis, et ka teisest küljest ähvardab hädaoht, ja tormas auto suunas. Autokastis istuvad mehed viskasid end hirmunult kasti põhja pikali. Stepan sõitis signaali üürates traktoriga karule järele. Lõpuks, taibates vaenlase üleolekut, tormas karu autost mööda põõsastesse ja kadunud ta oligi.

Esimees rääkis, kuidas aasta eest ehitati asula keskele ainukest kahekordset maja. Lähedal asuval väikesel platsil mängisid koolilapsed palli. Korraga oli võsastikust tormanud küla vahele umbes pooleteise-aastane karujõmpsikas, kellel on küll vana karu suurus, kuid lapse aru. Tavaliselt saadab sellist jõmpsikat ema. Küllap ta ei kavatsenud midagi halba, tahtis lihtsalt mängida. Hooga tormas ta pallile järele, sai selle enda kätte, pildus palli õhku ja jooksis jälle järele. Lapsed jooksid suure kisaga laiali.

Ehitusel töötas sel ajal ka Vasja Startsev. Tal oli millegipärast igal pool püss kaasas. Kuulnud kisa, jooksis ta püssiga lähemale. Kui kostis metalliklõpsatus püssiluku vinnastamisel, oli karupoiss nagu ärganud ja püüdnud põgeneda. Kahjuks oli ta hiljaks jäänud. Kostis pauk ja karupoeg prantsatas maha. Minu küsimuse peale, kas kahju ei olnud, vastas esimees: «Kui sa hakkad tundras iga looma pärast südant valutama, siis sured küll nälga.» - «Kuid ta oli ju alles laps,» kostsin mina. - «Karu on karu ja põdrakarjale teevad nad kahju kõik ühtemoodi,» lausus kolhoosiesimees piinlikuks kujunenud olukorda leevendades.

Väljas hakkas metsameeste hundikoer haukuma, katkestades tekkinud vaikuse. Tema haukumisele vastas paljuhäälne klähvimine. Ruttasime välja. Oli saabunud koerarakend, millel istus Uttel. Tema põdranahkse riietuse alla ei suutnud külm tungida. Kui me Utteli suurt külmataluvust kiitsime, hakkas Stepan naerma ja ütles: «Kohalike elanike riietus on nii soe, et nad võivad kukulli (tšuktši põdranahkne magamiskott) pugedes kõige suurema külmaga lumehanges ööbida.» Meile tundus see uskumatuna, aga sündmustest ette rutates pean nentima, et hiljem kogesime seda korduvalt omal nahal, kui hanejahil viibides magasime kümneid öid lageda taeva all kukullis, mis osutus suureks põhjapõdra talvisest nahast tehtud magamiskotiks, millel karvadega pool oli jäetud koti siseküljele. Väljas oli külma mõnel ööl -39 kraadi, magamiskotis külm ei olnud, ainult halb oli see, et koti küljest lahtitulnud karvad tungisid suhu ja nii oli lihtsalt ebamugav magada.

Kuigi Uttelil ei olnud külm, oli ta nõus meestega natukene istuma, sest alkoholi vastu oli peaaegu kõikidel kohalikel elanikel suur nõrkus. Klaasidesse kallatu vulises kurgust alla ja juttu jätkas meie noorim seltskonnakaaslane Miša Bogratšov:

«Kui mind esimest korda jahile kaasa võeti, olin kaheteistkümne-aastane. Olime kõik püünised üle vaadanud, saagiks saadud jänesed seljakotti toppinud, kui kuulsime imelikku nohinat ja ähkimist. Isa võttis püssi, vinnastas ja me hiilisime vaikselt läbi põõsastiku. Kuulsime, et keegi kõneleb valjusti, aga jutust aru ei saanud. 
«On seal keegi?» hõikas isa.

Kõik jäi järsku väga vaikseks. Istusime põõsa taga ja ootasime. Tükk aega ei olnud midagi kuulda, kuid korraga pistis meist paarikümne meetri kaugusel oleva kääbusseedermänni tagant pea välja karu. Meid märganud, keeras ta meile selja ja hakkas tuldud teed tagasi jooksma. Isa tulistas. Kostis jooksumüdinat ja murduvate okste raginat. Ettevaatlikult hiilisime karu põgenemise suunas. Viiskümmend meetrit eemal ta lamas - suur isane karumürakas. Vaatasin teda ja nägin, et ta silmades olid pisarad. Need olid suurte niredena üle koonu jooksnud. Mul oli vaesest loomast ääretult kahju. Tundus, et isa on inimese tapnud. See ebameeldiv tunne süvenes veelgi, kui isa oli karult võtnud naha. Karu meenutas hiiglase kasvu, hästi väljaarenenud lihastikuga meest. Pärast seda juhtumit otsustasin mitte kunagi karusid tappa, kuni seda on võimalik vältida. Vanadelt inimestelt olen ma kuulnud, et karud saavad kõigest aru, kui nendega õieti rääkida.»

«See on tõepoolest nii,» lisas Uttel. «Ka minu isa püüdis alati karudega kokkuleppele jõuda.»

Ta võttis klaasist lonksu ja hakkas jutustama:

«Nagu te teate, on karudel metsas üks puu, mille peale iga möödaminev mesikäpp küüntega kriipsu tõmbab. See on midagi sellist, nagu koertel ja huntidel post või kivi, mida kõik nuusutavad ja mille peale nad jalga tõstavad. Puu juures tõusevad karud tagajalgadele ja kraabivad sellele küünejäljed. Nende järgi on selgesti näha, kui suur loom on mööda läinud.

Kord ilmus küla lähedale suurim karu, kes siinmail on liikunud. Tema küünejäljed olid ligi meeter maad teistest kõrgemal. Karu tegi väga palju pahandust. Ta tappis rohkem, kui sõi, ja oli väga verejanuline.

Seda karu ei olnud keegi lähedalt näinud. Inimesed hakkasid kartma, et nad on ketlja ära pahandanud. Mu isa käis puud vaatamas ja rääkis siis teistele, et see karu on tegelikult väiksem kui teised, aga ta on lihtsalt väga tark. Ta oli mööda posti üles roninud ja siis küüntega puu peale jäljed jätnud. Muidugi ei usutud teda: isa jutu peale naerdi ja öeldi, et ta on päris segi läinud.

Isa otsustas karu üles otsida ja teda veenda, et ta oma halvad kombed maha jätaks ja ei tapaks rohkem kui toiduks vaja.

Ta kõndis tundras mitu päeva ja leidis lõpuks metsalise üles. See oli tõepoolest teistest väiksem ja peale selle veel küürakas. Ilmselt püüdis loodus loomale tehtud viga parandada talle antud terava mõistusega. Isa teadis karusõnu ja luges need talle peale. Samuti rääkis ta edasi külaelanike palved ära murra rohkem, kui sööd.

Karu oli algul isa jutu ära kuulanud ja end siis minekule asutanud. Korraga oli ta ennast aga ringi pööranud ja raevukalt isale kallale tormanud. Kuna isal ei olnud halbu kavatsusi, siis polnud ta ka relva kaasa võtnud. Loomulikult ta ei suutnud ennast kaitsta ja karu tõmbas tal kõhu lõhki. Isa oli pikali kukkunud ja karu ära mananud. Ta oli tollele ütelnud, et tema tapmisega on ka karul endal lõpp käes. Karu oli minema tormanud ja natukene maad eemal laukasse kukkunud. Laukas rabelemise ajal leidsid looma juhuslikult mööduvad jahimehed. Lärmi kuuldes olid nad lähemale tulnud ja mülkas rabelevale loomale püssipauguga lõpu peale teinud. Siis olid nad maast verise isa leidnud, kuid ei saanud teda millegagi aidata. Enne surma jõudis ta meestele üht-teist rääkida.

Jahimehed tulid külla ja jutustasid juhtunust. Tõotasin isa eest kätte maksta ja nii minust saigi «karutapja Uttel». Aga ma tapan ainult siis, kui selleks vajadus on. Miks karurahvast ilmaasjata vihastada?

Ise ma mõtlesin hiljem, et küllap tuul kandis lahkuvale karule ninna läheduses viibivate jahimeeste lõhna. Pidades isa meheks, kes on ta lõksu meelitanud, tormas ta vanale kallale. Millegi muuga ma seda seletada ei oska,» lõpetas vana jahimees oma jutustuse. 
«Nüüd on aeg teele asuda,» lisas ta pärast tekkinud vaikust.

Hea, et Koola matkad olid meid õpetanud ja et olime kaasa võtnud paar alumiiniumist suusanina, mis nüüd marjaks ära kulusid. Kerge vaevaga saime me murdunud suusa sellega sõidukorda. Seljakotid ja püssid viskasime nartale. Uttel sõitis koerarakendiga minema. Ka meie kolmekesi asusime teele. Nartajäljed viisid mööda jõekallast ülespoole.

Kuni liikusime saani jälgedes, ei saanud me arugi kitsaste suuskade ebaotstarbekusest. Nüüd aga vajusid nad metsas suure lume tõttu sügavale ja kohati sumasime me põlvini lumes. Ka esimehe kahe soonega suusad ei olnud paremad ühti. Kohalikud elanikud kasutavad põdranahaga ülelöödud laiu lapatseid, mis on tunduvalt praktilisemad tehasetoodangust. Nendega ei saa küll kiiresti sõita, kuid nad ei vaju ka sügavale lumme.

Rakendi jäljed viisid üle jõe ja hakkasid teise kaldaga paralleelselt jõe kallast mööda ülesvoolu suunduma.

Esimees suundus üle jõe ja meie talle järele. Kui me olime oma paar tundi suusatanud, keerasid nartajäljed ühele harujõele ja hakkasid mööda jääd ülesvoolu suunduma. Ilm hakkas hämaraks minema.

Mets muutis siin oma ilmet. Jõe kallastel oli näha kasvamas meile nii tuttavaid leppi, eespool hakkasid juba mingid suuremad puud paistma. Lähemale minnes tundusid need täitsa paplite moodi. Meie küsimusele vastas esimees: «Need ongi paplid.» See oli meile üllatus - paplid nii kaugel põhjas. Paplite külge olid seotud Utteli koerad ja taamal oli ka narta.

Esimesel pilgul me ei märganudki tema jahionni, sest see oli nii väike, madal ja mattunud lume alla. Ainult korstna järgi võis aimata, et tegu pole teps mitte tavalise lumehangega. Kujutage endale ette hoonet suurusega kolm korda neli meetrit või natukene väiksemat, mille katuseharja kõrgus maapinnast on poolteist meetrit.

Võtsime suusad alt ja läksime onni. Selle sisustus oli üpris kehv. Õigemini polnud seal mitte kui midagi peale paari nurgas vedeleva kasti, milles olid padrunid ja uued, veel kasutamata püünisrauad. Nurgas vedelesid kaks püssi, üks jahikarabiin ja teine väikesekaliibriline vintpüss, või nagu meil teda kutsutakse - sportpüss. Viimase erinevus meil kasutatavast oli selles, et tal oli all padrunisarv, mille pisikene magasin mahutas kaksteist padrunit. See püss oli Uttelil oravate laskmiseks. Ta ise rääkis, et oravale tuleb tulistada otse silma. Meile tundus selline täpsus fantastilisena, aga hiljem pidime vanade küttide täpsuses korduvalt veenduma. Nägin oma silmaga meest, kes kihutas kolmesaja viiekümne sammu pealt vene «kolmeliinilisest» vintpüssist kuuli karule täpselt kõrri.

Laudpõrandaga oli kaetud ainult kaks kolmandikku onni põrandast. Uksepoolsel osal oli muldpõrand, mille vasakpoolses nurgas seisis raudahi. Onn oli seest nii madal, et selle laudpõrandal saime liikuda ainult neljakäpakil. Minu pea puudutas istudes täpselt lage.

Onnil oli ka väike 30 x $40 \mathrm{~cm}$ suurune aken. Kuna onn ise oli praegu nagu suur lumehang, siis ei paistnud sealt loomulikult midagi. Isegi valgus kumas läbi lume väga nõrgalt. Onni valgustamiseks kasutati küünlaid või rasvalampi.

Utteli jahionnist kolmekümne meetri kaugusel asus teine, umbes sama suur ehitis. Erinevuseks oli ainult see, et ta asus nelja meetri kõrgustel postidel ja meenutas väga palkidest ehitatud tuvilat. Selles hoiti liha ja kinnipüütud loomade nahku. Kaitseks koerte ja metsloomade eest oli ta ehitatud postidele. Onni uks oli suletud puupööraga ja üles viis redel. Onni sisemuses asusid mitmesugused püünisrauad, et hoida neid eemal inimlõhnast. Enne lõksude ülespanekut määriti neid värske loomaverega, siis oli saak parem.

Kuna väljas juba hämardus, siis ei saanud me sel päeval enam midagi ette võtta ning ajasime niisama juttu. 


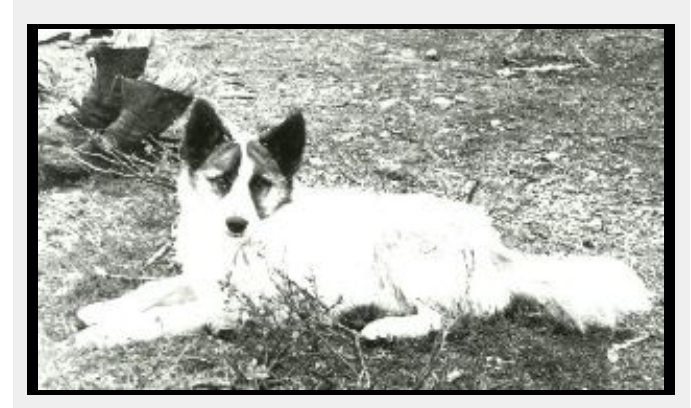

Vana Uttel tutvustas meile oma koeri. Kõige suurema ja targema nimi oli Palek. Ta oli rakendi juhtkoeraks ja kõik koerad allusid talle. Karujahil oli ta asendamatu. Tema julgus ületas igasugused piirid. Kui tavaliselt teised koerad ründasid karu selja tagant, püüdes hammustada vaenlast kandadest, siis tema tormas rünnakule alati otse, põigeldes kõrvale igasuguste löökide eest. Selline olevat olnud juba tema ema, kes vanemaks jäädes oli hukkunud karu käpalöögist. Välimuselt oli ta tõeline laika, turjakõrgusega 70-75 cm, värvuselt põhiliselt valge, ainult parem kõrv ja vasaku silma ümbrus oli must. Silma kohal, keset musta laiku oli pisikene valge laik. See oli nagu koera kolmas silm. «Selle silmaga ta näeb, kui ketlja tuleb,» ütles Uttel.

Veel kiiremini pidi ketlja ära tundma must koer, kellel on mõlema silma kohal heledad laigud.

Paleki karv oli küllaltki pikk ja saba pooleldi rõngas. Huvitavana mõjus tema roosa ninaots. Oma julguse, peremehe armastuse ja võib-olla kolmanda silma tõttu oli Palekil ainsa koerana õigus magada Utteliga ühes onnis, millist eelist ta meelsasti kasutas. Palek oli sõbralik nagu enamik Tšukotkal nähtud koertest.

Kuigi räägiti paljudest metsikute koerte rünnakutest inimestele, ei olnud asi juttudest kaugemale jõudnud. Tegelikult ei kuulnud me ühestki konkreetsest juhtumist. Hiljem selgus, et siiski liiguvad ringi metsikute koerte karjad, kes on palju hullemad kui hundid, sest nad ei karda püssipauke.

Näiteks Vasja Startsev jutustas, et teda olid kord jahilt tulles rünnanud metsikud koerad. Tal oli püss seljas ja ta ei saanud tulistada. Õnneks oli tal suur jahinuga, millega ta lähenevaid loomi peletas. Elu oli rippunud lausa juuksekarva otsas ning teda oli päästnud üks kalalt naasev tšuktš, kellel oli laetud püss nartas.

Palekile meeldis väga, kui teda silitati ja vastutasuks püüdis ta limpsida silitaja nina. Kunagi ei lahkunud ta peremehest kuigi kaugele, selle tõttu ei pandud teda ka ketti nagu teisi koeri, vaid lasti vabalt ringi joosta.

Kui Paleki ema hukkus, oli ta alles kolmenädalane. Väljas oli väga külm ja kuna Palekil ei olnud enam ema, kes teda soojendaks, siis toodi ta ahju ette nahatükile. Rumalast peast oli ta vastu punetavat ahjukülge puutunud ja oma külje ära kõrvetanud. Sellest venekeelsest sõnast palennõ $i$ tuletas tütar Niina koerale nime. Oli ta ju koolis vene keele õpetajaks.

Teine koer - Pušok - oli tõesti oma nime väärt. Ta oli, nagu nimigi ütleb, väga pehme pika karvaga, asendamatu oravate ja nugiste küttimisel. Leidnud jäljed, jooksis ta puu juurde, millel istus orav, ja hakkas, nööpsilmadega üles vahtides haukuma. Ta oskas lahti harutada ka kõige keerulisemaid sõlmi ja ei eksinud kunagi. Jahimehel oli nii üpris kerge saak üles leida ja kätte saada. Muud loomad sellele koerale huvi ei pakkunud. Karusid ta lausa kartis. Tundes karu lõhna, hakkas ta lausa värisema. 
Teiste koerte hulgas torkasid silma veel kaks koera. Üks oli süsimust laika ja teine hundikoera moodi. Need olid Muhtar ja Serõi. Mõlemad loomad olid väga verejanulised. Kui nad kuidagi suutsid ketist vabaks pääseda, siis tegid nad alati pahandust, tõmmates lõhki mõne põhjapõdra või muu looma, joostes jahile kümnete kilomeetrite taha ja murdes maha isegi metsikuid põhjapõtru. Kord kevade poole tõi üks põdrakarjusest tšuktš Muhtari ja Serõi Vaegi külla enne Utteli saabumist. Koerad olid lahti pääsenud ja kohe lähedal asuvast karjast ühe põdra murdnud. Kuna nad olid väärtuslikud rakendikoerad ja põdrakari kuulus kolhoosile, siis karjus säästis väljaõpetatud koeri. Ta ei lasknud neid maha, vaid võttis nad Vaegi tulles endaga kaasa.

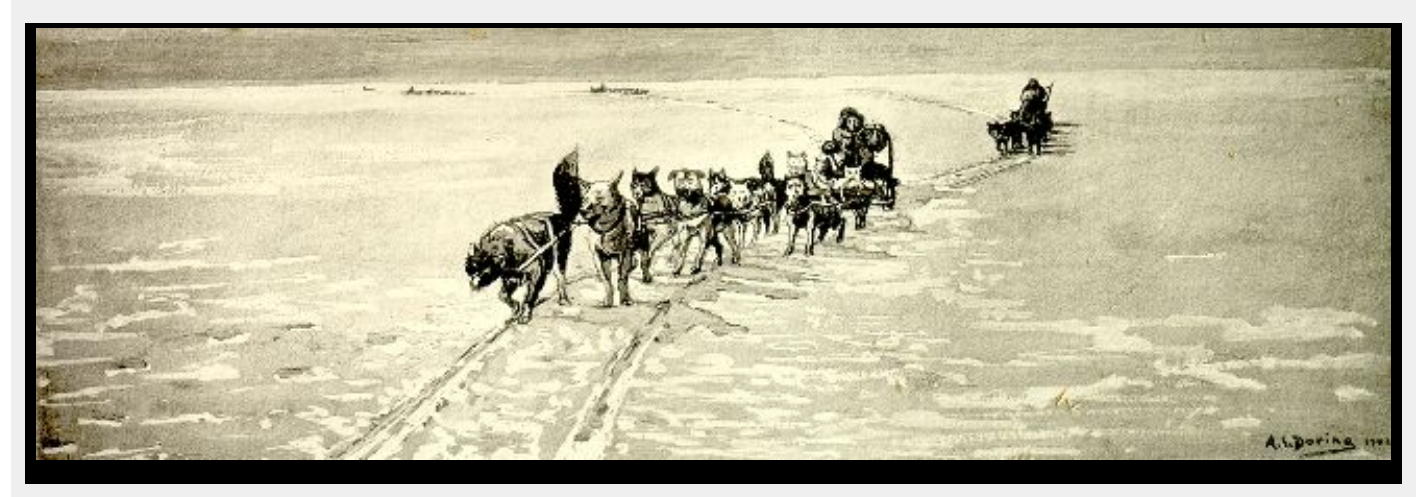

Ülejäänud rakendikoerad olid tavalised tööloomad. Ka neil olid mingid venekeelsed nimed, aga ma ei jätnud neid meelde.

Kuna väljas oli pime ja muud tegevust ei olnud meil võimalik edasi arendada, siis hakati uuesti mõistust teritama, sest kolhoosi esimehel oli vaba juurdepääs alkoholile ja ta oli üksjagu pudeleid jahile kaasa haaranud. Tollal maksis pudel puhast 96-kraadist piiritust 5 rubla ja 60 kopikat.

Kui alkohol jälle inimesed jutustama pani, lasi Uttel kuuldavale järjekordsed karulood.

Kord uidanud ta metsas ringi - sinna on nüüd oma viis aastat tagasi - ja korraga kuuleb, keegi kaebleb. Hääl muudkui tuleb tema poole. Uttel kükitab ühe kääbusseedermänni põõsa taha maha. Natukese aja pärast ta märkas, et tihnikus õõtsub mingi palgiots üles ja alla. Liigutajat ei olnud näha. Ta hakkas ennast uudishimust püsti ajama ja astus kogemata kuivale oksale. Terav praksatus kostnud tulijalegi kõrvu ja ta peatunud. Uttel kükitanud uuesti maha. Alanud hirmus ootamine. Vanal jahimehel olnud kõik kondid kangeks jäänud. Jalgu polnud all enam tundagi. Ilmselt polnud parem lugu ka selle palgi kandjaga, sest nott hakanud uuesti liikuma, ainult ta liikunud ettevaatlikult ja aeglaselt. Viimaks ilmunud seedritihnikust nähtavale ka palgi kandja. See olnud suur vana grisli.

Püssiluku metallilõgina peale ajanud karu ennast täiesti püsti, et paremini näha, kust see heli tuleb. Ometi ei visanud ta palki õlalt. Nüüd oli tema kõrgust näha. See oli tugevalt üle kolme meetri. Nagu ehitaja seisnud ta viiemeetrise palgiga õlal, suust ilusad teravad kihvad läikimas. Karu seisis nii soodsas asendis, et piisas ainult ühest lasust.

Siis selgus ka põhjus, miks karu palki kandis. Ta oli käppapidi sattunud püünisraudadesse, mis olid kinnitatud ketiga omakorda palgi külge. Lõksu sattudes ei jäänud vaesel mehel muud üle kui palk õlale võtta ja astuma hakata. Ju ei olnud lõksu panija arvestanud, et karu on võimeline palki seljas kandma, muidu oleks ta kinnitanud püünisrauad kasvava lehise külge. Kui kaua karu oli niimoodi rännanud, jäigi teadmata, sest ükski lähikonnas elavatest jahimeestest polnud teatanud oma lõksu kadumisest. Ju ta oli pärit kusagilt kaugemast külast. Arvestades, et lähima külani oli oma kolmsada kilomeetrit, pidi karu olema oma kaks nädalat käinud palk seljas. 
Teinekord, aastaid tagasi, oli Uttel pöördunud tagasi kalapüügilt. Lasknud paadil libiseda allavoolu, kui korraga märkas kaldal karujõmpsikat. See oli nii väike ja armas, et algul tärganud tal soov teisele kaldale sõuda ja karupoeg kaasa võtta. Samas turgatanud pähe, et küllap karuema on ka siin kusagil lähedal, ja ta sõudis paadiga põõsa varju. Tuul oli vastaspoolelt ja karupoeg ei aimanud mingit hädaohtu. Ta siblis põõsastes ja ilmus nähtavale koos vanema venna ja emaga.

Vana karu tatsas kohe vee äärde ujuma. Vanem poeg järgnes talle. Väike jõmpsikas katsus ilmse vastikustundega käpaga vett ja tormas põõsa poole. Ema urahtas vees valjusti, ujus kaldale, tormas poja juurde ja juba ta tuli tagasi niutsuv kera hambus. Viis poja sügavasse vette, kus teisel vesi üle pea, ja lasi lahti. Poeg karjatas. Siis ilmus pea puristades veest välja ja karupoeg hakkas kaldale ujuma. Kaldale jõudnud, hakkas ta ennast turtsudes ja niutsudes veest kuivaks raputama.

Peagi olid ema ja vanem karujõmm kaldal, raputasid ennast kuivaks ja mõne minuti pärast tõendasid ainult märjad jäljed kividel, et seal tõepoolest olid olnud karud.

Küsimisel selgus, et emakarul on vahel kaasas kahe pesakonna pojad. Poegi on pesakonnas üks kuni kolm. Pojad pidid sündima talvel, jaanuari lõpus. Huvitav oli kuulda, et vastsündinud karupoeg pidi kaaluma tavaliselt ainult 150-200 grammi ja nägema välja nagu rott. Ema jääb poegadega koopasse juuni lõpuni - juuli alguseni. Ka pärast koopast lahkumist jäävad nad mõneks nädalaks koopa lähedusse. Kolme aasta vanuselt ajab emakaru suured pojad enda juurest minema. Suured pojad ei suuda mõista, miks ema neid enam ei salli. Õed ja vennad jäävad veel mõneks ajaks kokku.

Poegade suurimaks vaenlaseks on täiskasvanud isakaru, kes murrab igal võimalikul juhul tulevased konkurendid maha. Siis hakkab poegadeta emakaru mõne aja möödudes uuesti indlema. Täiskasvanud isakarud hulguvad üksinda ringi. Augustis laskuvad kõik karud mägedest alla jõgede äärde ja jäävad ootama lõhede kudemist. Mägedest laskuvad nad alati ühte ja sedasama rada pidi ning isegi vanades jälgedes. Neil on sees nagu mingi sisemine kompass, et nad alati oma lapsepõlvekohtadesse oskavad tagasi tulla. Nii viivad mägedest alla sissekulunud jalajäljed. Lõhesid oodates teevad nad vees isegi trenni, hüpates kõhuli vette, pildudes kaikaid ülesvoolu ning neid siis jälle kinni püüdes. Nii harjutavad nad veel olematute kalade püüki.

Juunis karud paarituvad. Isakarud veedavad emakarudega umbes kaks nädalat. Enne paaritumist karud kurameerivad, nühkides päid vastastikku ja silitades teist looma käpaga. Isakarud võitlevad enne paaritumist omavahel tugevama õiguse pärast paarituda. Nõrgem karu taandub. Tihti saavad karud ise aru, kumb on tugevam, ja sel juhul nõrgem karu lahkub võitluseta.

Karud söövad liha igal võimalikul juhul. Neile kõlbab nii värske kui ka haisema läinu. Huvitav on see, et nad hõõruvad ennast haisema läinud lihaga või püherdavad raipe peal. Nad nagu ei saa sellisest lihast isu täis ja see tekitab nendes eufooriat.

Suuremad grislid võivad kaaluda oma viis-kuussada kilo ja on püstiasendis kuni 3 meetrit kõrged. Emakarud on isasloomadest poole väiksemad. Karud püüavad kokkusattumist inimesega vältida.

Pärast järjekordset lonksu klaasist alustas oma lugu kolhoosi esimees:

«Ühel päeval saabus kontorisse kohalik kalamees ja rääkis, et kalapüük on muutunud lausa võimatuks.

Peaaegu igal öösel käib võrke lõhkumas karu, kes kalu võrgust välja võttes tõmbab hammastega puruks ka võrgud. Küll nad on püüdnud karu hirmutada, aga tulemust ei miskit. Palub, et saadetaks mõni jahimees appi, kes vanakurjale tema õige koha kätte näitaks.

Saadetigi üks jahimees kaluribrigaadi juurde. Too ehitas endale puu otsa lavatsi ja jäi passima. Öö möödus pikkamööda. Kõikjal oli vaikne. 
Oli augustikuu. Ööd olid juba pimedad. Mees oli terve öö lavatsil lebanud, aga karu ei olnudki tulnud. Hommikul, pärast valgeks minemist, oli jahimees ülevalt alla tulnud ja kalurionni läinud. Ise kiitles, et näete, mina olen siin ja karu ei julgendki tulla. Heitis onni pikali, et ööväsimust välja puhata. Kalurid läksid võrkudest kala välja võtma. Tulevad suure kisaga tagasi, et tule ruttu, karu võrkude kallal.

Jahimees võttis püssi ja jooksuga randa. Jõuab sinna - võrgud katki, kuid karu jällegi kadunud.

Nii juhtus mitmeid öid järjest. Hakati arvama, et ketlja ise käib võrke lõhkumas.

Lõpuks hankis jahimees ühe tuttava vene ohvitseri käest lahingugranaadi. Kinnitas selle võrku kinni hoidva nööri ja kaika vahele, nii et nööri tugeval rebimisel tõmmatakse granaadi kaitseriiv ära ja 3 sekundi pärast toimub plahvatus.

Järgmisel öösel käiski hirmus mürakas. Kui valgeks läks, mindi asja uurima. Esialgu ei olnud näha midagi, kuid siis leidis üks kaluritest pasaraja, mis suundus metsa. Mindi seda mööda, kuni see veel näha oli, aga karust oligi ainult halb hais taga. Rohkem mesikäpp kalureid ei tülitanud.»

Siinkohal toon ära ühe toreda karuloo Otto von Kotzebuelt 1823. aastast, kui ta külastas tšuktšide naabreid kamtšatkalasi oma 1823.-1826. aastate ümbermaailmareisi ajal. Tema jutt kamtšatkalaste odaga karujahist sarnaneb vana Utteli jutustusega. Kotzebue lugu on järgmine:

«Korraldasime karujahi, mis meile palju lõbu valmistas ning mis end ühe vägevalt suure looma mahalaskmisega ka ära tasus. Siin on nii palju karusid, et mõne peale sattumiseks ei pruugi sadamast kuigi kaugele minna. Muidu nii pelglik kamtšatkalane ründab karu julgesti. Sageli ainult piigi ja noaga varustatult läheb ta karu vastu välja ja püüab teda ärritada. Kui karu end siis tagajalgadele püsti ajab, nagu see tal kombeks on, kui ta end kaitsma hakkab või rünnata tahab, torkab jahimees talle piigi rindu ning teise otsa maa sisse, mille järel ta karule noaga otsa peale teeb. Mõnikord aga jääb karu peale ning siis maksab jahimees oma julguse eest eluga.

Siinsete karude jultumusest annab tunnistust järgmine lugu. Aasta tagasi oli siin puudus kaladest, mis suviti on karude peamiseks toiduks ja mida nad ise jõgedest hangivad. Sellepärast tekkis karudel näljahäda ning nad ei jäänud terve talve jooksul talveunne, vaid luusisid ringi, isegi Peeter-Pauli tänavatele välja. Üks astus koguni majja, mille uks lahti oli, kuid tema taga juhuslikult kinni läks. Majaperenaine oli siin tavalise samovari just äsja keema ajanud ning selle esikusse seisma jätnud. Karu hakkas samovari nuusutama ja kõrvetas endal nina ära. Selle üle tigestudes laskis ta kogu oma viha samovari peale välja, haarates sellest esikäppadega kinni, surus endale vastu rinda, et pahategijat hävitada, mille juures ta end veelgi rohkem ära kõrvetas. Vihast ja valust vallapääsenud möirgamise peale tulid kõik majaelanikud ja naabrid kohale ning karu tapeti püssilaskudega läbi akna. Ta muutus surematuks seega, et sai siin kõnekäänuks. Kui keegi oma ägeduses iseendale kahju teeb, siis öeldakse, et justkui karu samovariga.»»1

Väsinuna päevasest teekonnast, paljudest muljetest ja piiritusest, pugesime magamiskottidesse ja uinusime.

16. jaanuari hommikul, veel pimedas, hakkasime end uuesti teele sättima. Uttel oli keetnud suure kannutäie kanget teed. Närisime konserve ja leiba ning rüüpasime teed, kuid õiget söögiisu polnud kellelgi. Kõiki vaevas jahipalavik või oli isu kadunud eilse piirituse tõttu.

Aga vanal oli aega küll. Ta toitis kõigepealt koeri kuivatatud kalajukolaga. Puhastas küünlavalgel oma püssi ja kui taevas juba hahetama hakkas, siis pani alles koerad narta ette. Küsis, kas me teist püssi tahame. Igaks juhuks lasime kaasa võtta, kuigi liisu järgi mina pidin pildistama. Hakkasime rakendi järel liikuma. Ronisime ühest sopkast üles ja teisest alla ja tee tundus lõpmata pikana. Lõpuks kästi meil hästi vaikselt liikuda ja rääkida ainult sosinal. 
Siis jäeti koerarakend ja meid kolme maha. Uttel läks laiadel, alt põdranahaga ülelöödud suuskadel vaatama, mis karu teeb. Tagasi tulles teatas ta: «Karu on õnneks veel koopas.»

Koerad jäeti maha, ainult Palek võeti kaasa. Otsustati, et esimesena tulistab esimees kui kõige tähtsam mees meie seltskonnas, teisena Eerik, ja kui vajadust on, siis mina. Uttel kui kõige kogenum, pidi kogu aeg meid julgestama oma jahikarabiiniga.
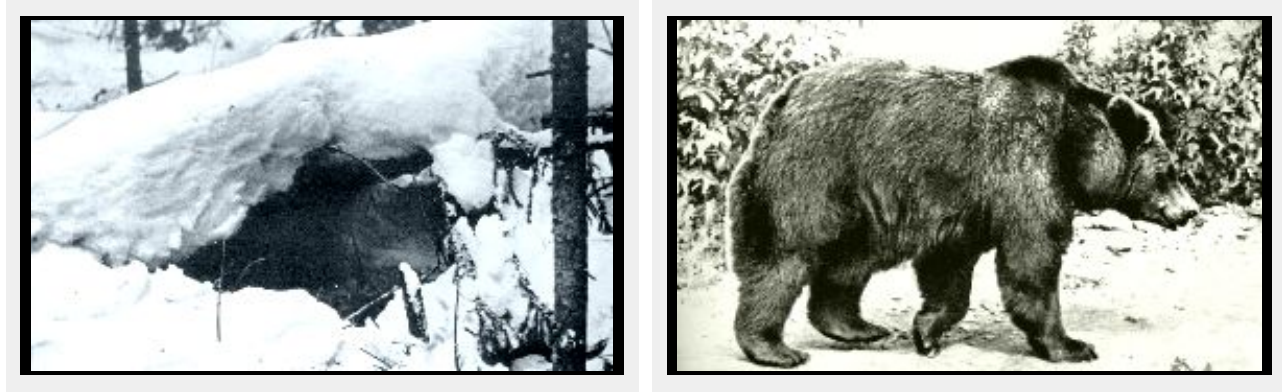

Karukoobas oli järsaku taga. Seal moodustas kaljusein süvendi, jäädes nagu katus karu pea kohale, kuna sissepääsu sulgesid kasvavad kääbusseedermännid ja kokkukantud oksad. Muidugi olid karud kõik lume all ning meie ei märganud midagi. Uttel andis käsu poolkaares kaljuseinale läheneda. Nüüd silmasime seina ääres tõusvat nõrka uduvinet. Käskluse peale: «Han! Han!» mis tšuktši keeles tähendab «võta! võta!», tormas Palek kaljuseina äärde ja hakkas lund kühveldama, ise valjult haukudes ja lõrisedes.

Ja siis see juhtus. Vaikselt lebanud lumi lendas korraga õhku ja järgmisel hetkel tormas lumepilv meie poole. Esimene ootamatusehetk hirmutas ilmselt ka Palekit, sest mõni sekund hiljem oli ta meie selja taga, et siis uuesti rünnakule asuda. Kui lumepilv natukene allapoole vajus, oli märgata selle keskel karu pärani lõugu. Valgus ilmselt pimestas karu, sest ta oli peatunud. Palek tormas uuesti tema poole ja karu püüdis teda käppadega rabada. Samal hetkel lajatasid kaks pauku. Karu vaarus ja prantsatas lumele. Mina sähvisin kogu aeg fotoaparaati klõpsutada. Uttel seisis, püss laskevalmis, kuid selleks korraks oligi kõik. Karu tõmbles mõned korrad. Mehed seisid laskevalmis püssidega. Koer rebis loomalt raevukalt raputades karvatuuste. Lumi karu ümber värvus punaseks. Ta tõmbles surmakrampides veel mõned korrad ja jäi siis vaikselt lebama. Palek püüdis teda veel siit-sealt sakutada, kuid mis surnud, see surnud. Vana kutsus koera ära, kes ilmse vastumeelsusega korraldusele allus. Pildistasin kõike ja kõiki, siis pildistati mind jne. Alles Eestis selgus, et minu vaev oli olnud asjata. Vene fotoaparaadi «Zenit-E» lintkatiku vahele oli arvatavasti tekkinud kondensveest jää. Lintkatik libises üle fotoaparaadi ava filmi valgustamata. Sama teed rändasid veel neli sellel talvel pildistatud filmi. Välja tulid ainult need pildid, mis Eerik pildistas suvel, kui me käisime külastamas kalureid, kes püüdsid ühel kõrvaljõel ketasid. Pettumus oli suur, aga see tuli muidugi hiljem. Praegu olime rõõmsad, süda põkslemas rinnus.

Ka Palek rahunes. Tema turris karv liibus ja ta hakkas isukalt lakkuma karu verd. Uttel läks narta järele. Me kraapisime lumme süvendi, nii et narta sinna sisse lükkamisel jääks maapinnaga enamvähem tasa. Rakend ilmus nähtavale põrgulärmiga. Suured koerad haukusid vihaselt, väiksed püüdsid kaasa aidata, aga hirm lõi neil hääle kinni ja näiteks Pušoki kurgust kostis ainult kuivi kiunatusi. Uttelil läks tükk aega koerte rahustamiseks. Veeretasime karu kuidagi nartale. Karu oli küllaltki raske. Esimees arvas, et oma $300 \mathrm{~kg}$ või üle selle. Noh, lõpuks oli ta nartal ja Uttel sidus ta nahknööriga narta külge kinni. 
Hiljem jahionni juurde jõudes hakkas Uttel karu nülgima. See toimus pärast kõhualuse sisselõike tegemist paljaste käte abil. Ainult haruharva kasutas ta mõne koha, eriti liha küljes kinni olevate kohtade lahtilõikamiseks põdrasarvest käepidemega nuga. Naha alt ilmus nähtavale tõeline atleedikeha, eriti oli arenenud esikäppade muskulatuur. Tagajalgadel oli lihastik tunduvalt nõrgem. Sama lugu oli ka küüntega. Esikäppadel olid need suured nagu inimese sõrmed. Kole oli mõtelda, mis tunne võib olla, kui ta niisugustega su pead silitab. Tagajalgade küüned olid ligi kolm korda lühemad.

Kui me kiitsime karu muskleid, ütles Uttel: «Miks ei peaks nad sellised tugevad olema, kui karud teevad treeningut.» Me ei uskunud oma kõrvu, arvasime, et Uttel teeb nalja. Siis ta jutustaski: «Kord tulin mööda jõe kallast. See koht oli siit oma $30 \mathrm{~km}$ allavoolu. Seal on üks kallas tasane, teisel pool on kaljud peaaegu püstloodis seintega. Niisuguseid järske paljandeid on seal oma tosina jagu järgemööda ja neid kutsutakse kaheteistkümneks õeks. Kõnnin seal lähedal ja korraga sulpsti! kukub ülalt ühe õe otsast kääbusseedermänd alla. Esimesel pilgul ei märganud midagi. Arvasin, et kallas variseb. Siis aga lendas teine känd ülevalt alla. Vaatan ja näen - üks karu vaatab ülalt alla, kuidas seedritüügas sulpsudes vette kukub. Läheb eemale järsaku varju. Sain aru, et järgmise tüüka järele. Tõmbas kääbusseedermänni koos juurtega maa seest välja ja ilmus jälle kalda peal nähtavale, et seda alla visata. Jälgisin teda tükk aega. Kui ta järjekordset kändu üle pea visates oli seljaga jõe poole, siis vilistasin. Karu ehmatas ja lasi endale seedermänni juurika vastu pead. Ega tema peagi rauast ole. Lendas nagu kera ülevalt alla ja prantsatas vette. Kärestikuvahus kaduski ta minu silmist.»

Jutustamise ajal jätkas vana nülgimist. Varsti asus ta looma soolikatest puhastama ja liha tükkideks lõikuma. Liha lõikumisel tarvitas ta ainult nuga. Eestis on jahimeestel alati kirved kaasas, et liha lahti raiuda. Tšuktšid on selles suhtes meist osavamad nagu ka paljudel muudel aladel, mis puudutavad loodust.

Kui me hiljem põdrakarjustena kuut tuhandet kilomeetrit piki Tšuktši poolsaart ringi marssisime, siis veendusime selles pidevalt. Tuli tehakse üles ühe tiku abil, isegi siis, kui kolm nädalat on järjest vihma sadanud ja puud kõik märjad. Tuli saadakse üles ka siis, kui tikke ei ole, kasutades süütamiseks tulekivi ja taela või siis puutükke ja sammalt.

Karude tarkuses veendusin ka ise. See juhtus mõni kuu hiljem. Kord istusin pärast karjaskäiku kivil ja vaatasin binokliga lähemat ümbrust. Eelmisel ööl oli olnud äike ja sadanud kõvasti vihma. Öö oli olnud pime. Põdrakari oli kokku aetud ja moodustas ringi. Korraga olid loomad tormanud karjustest mööda, nii et karjused jäid põhjapõdrakarja ja karude vahele. Karud olid siiski rünnanud karja, teised karud olid oodanud põtru karjuste selja taga. Lihtsalt ühed karud ajasid põdrad teiste käppade vahele. Välkude valguses märkasid karjused aeg-ajalt karusid ja tulistasid neid. Hommikul leiti, et siin-seal olid maas vereloigud. Nii et karud olid oma saagi saanud, mispeale karjused otsustasid neid karistada ja mõned maha lasta.

Märkasin binokliga eemal tundras mitut karu, aga need olid liiga kaugel.

Korraga nägin üht karu kõndivat kõrvalsopka külge mööda alla orgu. Võtsin püssi ja ronisin sopka otsa. Karu märkas mind ja peitus kääbusseedermänni tihnikusse. Mina peitsin ennast mäenõlvale kivi taha. Tund möödus, karu laskeulatusse ei ilmunud. Aeg-ajalt kerkis ta pea siin-seal kääbusseedermänni tagant välja, aga ta oli kaval ja varjus samas. Vihma hakkas sadama ja ma otsustasin lähemale minna. Karu oli kadunud. Kui ma jõudsin nende põõsaste juurde, kuhu karu oli peitunud, ei näinud ma kedagi. Vaatasin tagasi sopka otsa ja nägin, et selle kivi otsas, mille taha ma olin ennist peitunud, seisis pruunkaru ja vahtis ülevalt alla minu suunas. Tulistasin, kuid vahemaa oli liiga suur ja ma ei tabanud. Karu vangutas mäe otsas pead, nagu mind halvustades, ja kadus sopka taha. Kas oli see seesama karu, keda ma all nägin? Sel juhul oli ta väga vaikselt ja kavalalt 
hiilinud sopka otsa. Või oli see teine karu? Sel juhul olid nad omavahel kokku leppinud minule jahti pidada. Kuna ma muutsin oma asukohta, siis see neil ei õnnestunud. Mine tea, mis muidu oleks juhtunud.

Meie edukas jaht oli seekord lõppenud ja valmistas mulle suure pettumuse. Mõlemad karu tabanud lasud olid surmavad. Üks kuul oli tunginud pähe ja teine südamesse. Kaks silmapilku ja karu oligi surnud. Antud olukorras pole loomale jäetud mitte mingisugust pääsemisvõimalust. Ta tuleb unise peaga koopast välja, päike paistab silma. Ta ei näe midagi. Kõlavad lasud ja ongi jaht läbi.

See on jahil alati nii. Ootad, loodad midagi. Sind valdab kirg. Aga pärast on kahju või isegi kurb. Kui kutsutakse, siis lähed aga uuesti ja uuesti. Ilmselt on see ürginstinkt või püüd end proovile panna.

17. jaanuari õhtuks viis traktor meid Vaegi tagasi. Karupeiede ajal oli meil suupisteks keedetud karuliha. Kuigi need peied ei olnud mingid peied. Istusime lihtsalt jahiseltskonnaga meie korteris ja võtsime viina, mida kolhoosiesimehe lahke süda lubas meil laost osta. Karuliha maitsel ei olnud väga vigagi, aga keetmise ajal haises ta nii, et hoia nina kinni. Uttel seletas, et see on sügisel söödud kaladest ja selle pärast keedetakse karuliha külas alati õues lõkke peale pandud pajas.

Karunahk kaunistab arvatavasti siiamaani kolhoosiesimehe elamist, kui koid pole nahale lõppu peale teinud. Trofee kuulus temale kui esimese surmava lasu tegijale. Karuliha jagati külaelanike vahel ära. Külaservas asuvast šamaani jarangast oli kuulda mitu päeva bubini (tšuktši ümmargune koeranahkne trumm) häält. Kuna me olime alles külla saabunud ja meid ei peetud omadeks, siis meid ei kutsutud tšuktšide karupeiedele.

\section{Kommentaarid}

1. Otto von Kotzebue 1978. Reis ümber maailma. Tallinn, lk 167. 